\title{
Professional Ethics of Designers in Academic Process According to V. Papanek
}

\author{
Olga Savvina \\ Department of Ethics \\ Peoples' friendship university of Russia \\ Miklukho-Maklay str., 10/2, Moscow, Russia, 117198 \\ E-mail: savvina_ov@pfur.ru
}

\begin{abstract}
The article analyzes professional ethics of designers and educational process of students in design school according to the American designer Victor Papanek. He argues that industrial design is a very significant field of human activity, and that is why an industrial designer has a responsibility to the world. Social good and moral values are very important in a designer' practice and V. Papanek tries to embody them in the educational process. The article analyzes Papanek's project of design school in the framework of academic ethics, the possible usefulness for the contemporary academic ethics, and educational management. The project contradicts market mentality in education as well as in design profession, but it aims at the social good and moral values of the profession. The author proposes that Papanek's views on the educational process can be extrapolated to higher education of other specialists.
\end{abstract}

Keywords-design; professional ethics; academic ethics; social good; social responsibility; educational process

\section{INTRODUCTION}

"Design for the Real World" by Victor Papanek was published in 1971 in New York. Since then, it was translated into many languages and republished not only in the USA but in many other countries. V. Papanek wrote other books and articles, as well, but "Design for the Real World" is the first and the most famous, inspiring young designers all over the world. The book is not only about design itself, but it is also about professional ethics and moral values of designers. Usually, books on professional ethics do not inspire youth and are considered rather dull, but Papanek's work is a rare exception. The book also contains a chapter about higher education of designers and organizing educational process. The author describes his views on design schools, their advantages and disadvantages and his ideas of what should be a design school. His higher education of designers is in accordance with the professional ethics and design for the real world being devoted to the social good.

The aim of the article consists of two steps. The first is to analyze Papanek's views on design, higher education for designers (design schools) and the place of professional ethics in his project of design school. The second is to consider the viability and efficiency of his project of design school, possibility to extrapolate his principles or system of

Funding: № 101402-0-000 "Professional ethics in academic environment: modern problems". education to other institutes of higher education. The main ethical aspects of Papanek's views on education for designers have been presented in the previous work [10].

\section{THE CONCEPT OF INDUSTRIAL DESIGN BY VICTOR PAPANEK}

Victor Papanek wrote in the preface of his famous book "Design for the real world": "There are professions more harmful than industrial design, but only a very few of them" [7. P. 3]. This statement shows us that industrial design for $\mathrm{V}$. Papanek is not only harmful, but also very important, because useless and inconsiderable activity or profession cannot be very harmful for people. There are importance and ubiquity of industrial design in this sentence, and at the same time the author argues that industrial design does not work right.

Papanek understands design in the broad sense: "All men are designers. All that we do, almost all the time, is design, for design is basic to all human activity" [7. P. 3]. All human beings are constructing and structuralizing their environment, and designers are professionals in this field. The impact of their work is high, and it has been increasing for the last decades. "The ultimate job of design is to transform man's environment and tools and, by extension, man himself" Papanek says [7. P. 3]. It means that the social impact of designers' work is very high, and, consequently, the responsibility of a designer is also very high. The study of P.-P. Verbeek confirm Papanek's viewpoint [12]. The author argues that technological artifacts have moral significance and "technologies play an active role in moral action and decision-making" [12. P. 93]. According to P.-P. Verbeek technologies and technological artifacts establish a relation between users and their environment. These relations have moral aspect and different characteristics of artifacts influence on decisions and social attitudes.

V. Papanek considers function as the first requirement to products of industrial designers. A chair should be comfortable first of all, it is not an object of art or a thing designed to show its owner's richness. Furniture, children's playgrounds, cars and other products of industrial design should be functional and safe for users. Papanek collected strange and useless things and machines "idiot-gadgets" [2. P. 79], artifacts of Western consumer culture. He opposed 
indigenous cultures to the modern consumer culture that produced products to sell and satisfy "phony wants" rather than make functional products and solve problems of the real world. The book "How Things Don't Work", written with coauthor J. Hennessey, illustrated the absurdity of commercial design producing "hazardous lavatory bowls" [2. P. 79]. Papanek loathed status demonstration and things which serve this aim.

V. Papanek writes that somebody can think that beauty and aesthetics are also very important and, may be, as important as function. He agrees that aesthetic makes things "beautiful, exciting, filled with delight, meaningful" [6. P. 7]. Moreover, design must be meaningful. But the author of "The Design for the Real World" formulates the rule: if a thing is functional, it is beautiful automatically. The next rule for designers should be the following statement: things exist in the context. For example, Japanese floor mats are done to "absorb sounds and to act as a sort of wall-to-wall vacuum cleaner which filters particles of dirt through the woven surface and retains them in the inner core of rice straw" [7. P. 18]. Tatami keep Japanese feet in soke-like tabi clean. Tatami is functional in the context of Japanese traditional culture, but, with increasing use of western shoes, these mats do not work. To add, they are quite expensive. Another rule that helps designers to make functional products is usage of materials affordable on the territory where final consumers live. It decreases price and problems with delivery of the product.

The next principle of design is economy of materials. If it is possible to reduce materials in the production process without lacking of functionality of the product, a designer must do it. This measure also reduces a price and increases the affordability of the product.

Lastly and most importantly is the following: design must benefit this world, solve real problems and not serve consumerism. Consumer culture encourage designers to make things for sale, but not to make useful things for solving global problems: ecological crises, poverty, starvation, natural disasters and others. Design must be moral. According to V. Papanek, designers must dream of making the world better. It is his professional duty and this duty is more significant than salary or glory. V. Papanek took part in many projects in developing countries trying to make poor people's life easier, save fields from soil erosion and dealing with ecological problems. He dismissed commercial design as "the perversion of a great tool" and called on designer to fulfill genuine needs [8]. Moral aims must determine an industrial designer.

New technologies change people's life, economical and social relations, and sometimes the technology implementations influence on labor market. People are losing their jobs, and their families end up facing difficult economic problems. It means that a designer can harm middle and low class people introducing new projects and technologies. Analyzing this ethical issue in the chapter "Doit-yourself murder: the social and moral responsibilities of the designer", Papanek comes to conclusion that "designer's responsibility must go far beyond these considerations" [7. P.
55]. The question that should be asked by designer: "will his design be on the side of social good or not".

It is worth to note that for V. Papanek, industrial design is a powerful tool to change reality. Concluding his considerations, we can apply one of the first principles of medical ethics "Do No Harm!" established by Hippocrates for physicians to industrial designers. Social good is the mail goal of a designer. He must think about it before doing his work.

V. Papanek died in 1998, but his book, "Design for the Real World", still encourage young designers worldwide.

\section{THE CONCEPT OF HIGHER EDUCATION OF DESIGNERS BY V. PAPANEK}

Papanek's views about designers' education are written in "Design for the Real World", chapter "The neon blackboard: the education of designers and the construction of integrated design teams". The author follows John Dewey's principle of education: the unity of theory and practice. Knowledge must be used in practice. For example, Dewey considered learning dead languages, taught in the beginning of the $20^{\text {th }}$ century in the USA, as useless and even harmful because students would never use this knowledge, and they would lose their skills without practice. Students needed this knowledge only to pass the exam. After the goal was achieved, they would begin to forget the knowledge they had been learning for a long time period [3. P. 1-25]. Meanwhile, the world is changing, and the modernity requires other skills and knowledge.

The first fact Papanek disliked was that graduates were searching for a job place with appropriate wage in big commercial companies. The business was not interested in moral norms and social problems of the world, lives of millions of people living in poverty and problems of disabled children. Profit and consumer behavior of the Western average men were much more desirable for commercial companies than real problems. Environmental crises is also the field where design can help and solve many problems, but only a few organizations were looking for designers to contribute to the innovations which could be useful in environmental protection or wildlife management. Papanek encourages young designers not to follow the way commercial companies offered them and serve commercial design, but try to follow morality and act. We active in achieving moral aims, waiting for appropriate circumstances will not help the real world. If a designer decides to be moral, he must be strong, consistent and active.

Ethical education is very important in the context of designer education according to Victor Papanek. Because, as it stated above, it is very difficult for young designers to follow real aims of the profession. He wrote that ethics or professional designer ethics should be the part of education in universities on designer faculties. The practice showed that teaching professional ethics for designers brought fruitful results [5]. In the Institute of Graphic design of SaintPetersburg two groups of students was compared. The first group is 6-year students studied in accordance with the curricula of the previous generation without course of 
professional ethics. The second group is 1-year students studying in baccalaureate according to the new program; they have attended the course "Introduction to ethics of contemporary design". The course is studied in the first semester of the first year, it is 144 hours long and the students receive 4 credits. The research showed that $74.3 \%$ of the 6-year students did not understand the social impact of their profession; $14.3 \%$ of them thought that it did not worth to deal with social problems in designer profession; only $11.4 \%$ considered that designers had a significant social responsibility [5. P.70]. The results of the survey of 1-year students were quite different. $82 \%$ of responders thought that designers had a great responsibility to the society; $8 \%$ argued that it would not correct for designers to deal with social problems and only $2 \%$ did not understand social significance of their profession. Moreover, the majority of the 6-year students considered that there was no need in ethical education for designers, they could not define the notion "professional ethics" [5. P. 71]. The notions of "affordable design" and "affordable for everyone" were associated with "cheap design" among these students. The mentioned notions had another, deeper meaning. Only talented and experienced designers can make things popular, beautiful and widespread. The students of the 1-year recognized the significance of design for society and were ready to deal with social problems. This study presented the results of the theoretical course of ethics, but it was beneficial for young people and helped them to understand the social value of their future profession.

Papanek wrote that ethics lectures were useful and important, but it was not enough. A young designer must practice from the first year in the university. "The learning must be an aesthetic experience" [7. P. 286]. If we formulate Papanek's principles of higher education of designers, the first is the unity of theory and practice and the second is the social good as the last aim. With theory and practice, these two components of design education should aim for social good: "The main trouble with design schools seems to be that they teach too much design and not enough about the ecological, social, economic, and political environment in which design take place" [7. P. 291]. That is why tasks for students should be a part of real projects. Papanek criticized "creative" tasks like projects of "building casino on Mars". These lessons would never give the needed skills to future designers; student would never see the results of their work. Taking part in real projects would give students feedback quite soon, and it would give them motivation to change the world and create new projects.

The third principle regards advanced training and greater specialization instead of narrow specialization. This approach will give the opportunity to think broadly, what is the essential characteristic for solving real problems. A narrow specialist hardly can quickly find new materials, suitable forms and colors and see a solution. Establishing the 5-year undergraduate curricula for environmental and industrial design, Papanek attempted to break down the division between visual design, environmental design, interior design and other types of design. According to the curricula, students study different courses from different science and fields like chemistry, physics, computer science, electronics, anthropology, social sciences, psychology, life sciences and etcetera. One-third of the curricula and undergraduate time is devoted to free elective courses. It gives students the possibility to choose the area they prefer that is of concern to them such as political science, history of the $20^{\text {th }}$ century, or so on. This approach was in accordance with Humboldt model of the university developed in the beginning of the $19^{\text {th }}$ century. One of the principles of Humboldt's university model was the freedom of education. Students could choose courses they passed in the framework of the model. Humboldt considered freedom as one of the most important characteristics of a person and argued that higher education might develop freedom of thought in young people [11]. The university model of the German philosopher and governmental official has been spread all over the world, and, even today, it is still topical. Papanek also paid attention to future designers' freedom in studying, developing their personal abilities and satisfying their professional interests. In addition Papanek's approach to design schools corresponds with J. Ortega-y-Gasset's views on higher education. The Spanish philosopher wrote that the main aim of a university was to integrate the youth into cultural context of the contemporary world. Every university should teach students the following courses: 1) physics (physical world picture); 2) biology (foundations of organic world); 3) history (historical development of Mankind); 4) sociology (the structure and function of society); 5) philosophy (the plan of the universe) [6. P.45]. A designer, if he is going to change our environment and benefit mankind, must be integrated in the cultural context of his modernity. Learning different fields of knowledge will help students in achieving their goals - to be broad-minded specialists, ready to solve topical social problems, and define the fields where their skills will be useful.

The forth principle of design education is closely connected with the previous one - it is working in crossdisciplinary teams. The contemporary teams contain specialists from different fields including art, engineering, life sciences and others, people of different social groups. A project will be efficient only if we apply knowledge of specialists from different fields. Papanek worked in the teams included poor rural people without formal education, small children and mentally disturbed patients [7. P. 304]. Despite the fact that communication was difficult, the teams achieved their aims in every project. Moreover, crossdisciplinary teams not only solve problems but they also have a potential in looking for new or implicit problems waiting for solutions. Papanek gave some examples of design problems that needed cross-disciplinary teams. The children's playground was among them. Here are the characteristics of materials and project of the playground which might be taken into account: "a) extremely hard wear and use; b) frost, ice, snow, storms and hard rain; c) prolonged use over a period of five to fifteen years; d) dangers of shearing, splintering, torque, or fracture while being used by a child; e) toxic characteristics of the various materials and coloring agents; f) perceptual and psychological responses of children (at various age levels) to the colors used; g) relative ease of care, maintenance, repair, 
and replacement of equipment" [7. P. 310]. These questions cannot be solved by a group of narrow specialists in the field of industrial design; they require the participation of specialists in the field of children's psychology, information about the climate of a region where the playground will be, chemical and physical characteristics of materials and etc. And it not full range of questions, there are also the problems like "number of streets to be crossed by children hoping to use the playground; illumination of the playground at night" [7. P. 310] and others.

The fifth principle can be formulated as "designer teams must work in local regions". Nobody can solve a problem sitting in an office, especially problems of developing countries. Papanek gave examples of design projects of European specialists that did not work in the developing world. Architectures could not provide low-cost projects of houses for African countries without being in Africa; industrial designers could not make things which would be in the context of the people's everyday life. The peasants of a village in one of the developing countries did not use plough, provided by European designers, arguing that iron "offended" the soil and Earth. A designer team must work in local region to avoid these unpleasant mistakes. Otherwise a team risks not only losing money, but also losing confidence of local community.

Following the principles above, academic officials, designers and teachers will give young designers valuable curricula and learning experience which will give the youth not only ability to change the real world, but also the pursuit of professional ethics, moral values and social good. After graduating from a university a designer will "feel a little ashamed when he designs a pretty, sexy toaster..." [7. P. 321].

\section{PAPANEK'S MODEL OF EDUCATION FOR DESIGNERS IN THE FRAMEWORK OF ACADEMIC ETHICS}

The five derived principles address the issues of ethics and efficiency of higher education. Papanek's model of education meets the principle of freedom of learning and teaching Humboldt's University model: students are free to choose courses they learn and teachers are free to establish contents of courses they teach. V. von Humboldt established the second principle: unity of education and scientific research. This principle transforms into unity of theory and practice in Papanek's variant of design school. It is obvious that Papanek's principle is the particular case of Humboldt's one. There is no information about Papanek's awareness of Humboldt's University model, but his education for designers follows Humboldt's principles of university, developed and written almost 200 years ago. Humboldt's university model was developed by the German governmental official in order to make university viable, give it ability to change with the world and science. Humboldt's model was developed to follow a state's aims also: preparing future stuff for governmental purposes and governmental aims is one of a university's tasks. The university's structure was integrated into governmental management and governmental officials took part in the university's life, university professors sometimes got the status of governmental official [1. P. 463-502]. Papanek's design school is not directly connected with the state, Papanek is more interested in social and global problems of the modernity than in governmental affairs and he does not pay much attention to the relationships between state and universities.

At the same time Papanek's model meets J. Ortega-yGasset's concept of university mission. The Spanish philosopher considers the integration into cultural context of the contemporary world as the aim and mission of the university (1933). Victor Papanek is sure that designer's work is useless, harmful or strange without immersion in cultural context. Fulfilling particular projects, a designer should learn information about local culture, traditions and beliefs, economic, social and other peculiarities. He, as Ortega-y-Gasset, thinks that students should learn different disciplines and sciences in order to achieve the aim - cultural integration. Papanek never wrote about the work by J. Ortega-y-Gasset "Mission of the University" but his attitudes toward mission of higher education is in accordance with Ortega-y-Gasset's concept.

Papanek described his understanding of industrial design and formulated statements of professional ethics of designer in his "Design for the Real World". He wrote that he disliked, may be, even loathed commercial design because it did not follow professional ethics and searched for profit rather than do useful things people needed. He did not like compromise with the market of "phony wants". He gave an example when a chairs, designed by the student, had been sold quite successfully [7. P. 303]. The reason of this commercial success was that the chairs were of high quality and the developer thought of how to make the chairs comfortable and did not calculate profit he would receive. Ethics and social good became the core of Papanek's education for designers, he refused any compromises with designing "sexy toasters".

At the time when Papanek was writing his books and taking part in design projects in developing countries, academic community was turning to market. The famous book by Bill Readings "University in ruins", printed in 1997 expressed the idea that universities worldwide had transformed into bureaucracies providing students-clients with educational services. Readings wrote that contemporary capitalism became international and it was influencing on all spheres of our life including higher education. Readings claimed that Humboldt's university model did not work anymore, and decreasing significance of a state in the world global market was one of the reasons. "Culture" as the symbolic and political counterpart to the project of integration purchased by the national state - has lost its purchase" [9. P. 12]. It means that culture is losing its role with the state, giving way to global market with international commercial companies. Now the global market establishes values, and the main aim of the universities, as Readings writes, is the development of "human recourses" for the marketplace instead of "national culture".

Exactly this idea of making "human recourses" for "phony wants" of clients of international companies was 
loathed by Papanek. Perhaps he would never agree with the idea of the university of "excellence" on the market of educational services. This idea lacks the connection with real problems Papanek writes about. The disconnection of Papanek's views on education and the modern trends in academic community is the illustration of the fact that morality and market values hardly can be combined. The professional life of Victor Papanek was a crusade against commercial design and commercial values. His ideas were spreading; some of them were used as a concept of commercial companies like "Ikea". Papanek succeeded in his profession despite his views on commercial values and the era of capitalism. It seems that his ideas of education have a great potential in the future, and they are very topical today. His ideas can benefit contemporary higher education. Nowadays, the concept of "Triple Helix", meaning university-business-state, is a popular idea in academic ethics [4]. These parties brings to higher education their values and ethical norms. For example, a state brings the values of patriotism, national culture; traditionally, a university keeps the values of the search for new knowledge and transferring knowledge to younger generations. It is considered that business values have brought creative thinking, ability to find necessary information, skills of scientific research into academic community and academic life. Openness to new technologies and information, rapid response to challenges of the contemporary world became new requirements to universities and professors, and these characteristics are based on business values of the global market. Business ethics has helped universities to archive new goals and uphold new standards combining them with the principles of Humboldt's university model. But the "Triple Helix" lacks the main idea of Papanek's design school - the social good. Real problems of the real world are still waiting for solutions. Integrating of Papanek's principles into the mission and structure of the contemporary university will help to educate new generations in accordance with morality, social good and practical actions.

\section{CONCLUSION}

In this paper we analyzed the main Victor Papanek's ideas, considering the education of designers. These ideas are based on his understanding of professional ethics of designers. He emphasizes the important role of designer's social responsibility and an impact of the profession on human environment and humans. That is why Papanek tries to put into effect professional values of designers in the educational process from the students' first year in the university to graduation. Moral values of the professional ethics are the core of educational process according to $\mathrm{V}$. Papanek. Knowledge and practice have the same significance as morality and they must be intrinsically linked. I argue that this statement is a very important Papanek's innovation that should be taking into account by institutes of higher education.

The principles of Papanek's design school have been derived from his book "Design for the Real World". These principles are 1) unity of theory and practice; 2) social good is the aim of the profession and educational process; 3 ) greater specialization; 4) cross-disciplinary teams working with designer projects; 5) developing projects in local region.

The first and the second principles can be combined in one principle - the unity of theory, practice and moral values. Despite this principle containing a methodological part (unity of theory and practice) and a vector of educational process (moral values), the principle has a potential in academic ethics and academic management. It is noted that Papanek's "social good" has been transformed into "moral values" in order to apply the principle to education of other specializations, extrapolate Papanek's approach to higher education of other universities which are not connected with industrial design and professional ethics of designers.

The analysis of principles of Papanek's design school and Humboldt's university model shows that they have much in common. Papanek shares the idea that students are free to choose disciplines (but only one-third of them), and teachers are free to organize courses and contain them. Humboldt's principle of unity of scientific research and education is also reflected in Papanek's design school: university teacher must be practicing design. Humboldt's principles have been proved by the time and their similarity with Papanek's educational ideas promise viability to Papanek's design school. The mission of the university by J. Ortega-y-Gasset integration students into cultural context of the contemporary world can be found in Papanek's educational concept. Modern trend in academic community and university management - orientation to labor market is not a part of Papanek's university. His main idea is the social good that often contradicts commercial design. Papanek's inventions and ideas have found their place on the market, despite loathing the market mentality in the profession. The contemporary higher education pays to much attention to market values [9], and I suppose that Papanek's educational ideas will be very fruitful for the academic community and will be able to establish a counterweight to market mentality in higher education.

\section{REFERENCES}

[1] Andreev, A. Russian Universities of the $18^{\text {th }}-$ the first part of the $19^{\text {th }}$ century in the context of university history in Europe, Moscow, 2009.

[2] Clarke A.J. The Anthropological Object in Design: From Victor Papanek to Superstudio, in Clarce A. J. (ed.), Design Anthropology, Springer-Verlag, Wien, 2011.

[3] Dewey J. Democracy and Education: An Introduction to the Philosophy of Education, Indian edition, Aakar books, 2004.

[4] Ickovic, G. (2010). Triple spiral. Universities-enterprises-state. Innovations in action, Tomsk: TUSUR.

[5] Nikul'shina, L.V. The development of the ethical values of future designers as a topical problem of their professional education, The Bulletin of Leningrad state university by A.S. Pushkin, issue 1, Vol. 3 2015, pp. 67-72, URL: http://cyberleninka.ru/article/n/formirovanieeticheskih-tsennostey-buduschih-dizaynerov-kak-aktualnayaproblema-ih-professionalnoy-pod gotovki

[6] Ortega y Gasset J. Missiia universiteta (Mission of the University), trans. by Golubeva M.N., Ed. By Gusakovsky M.A. Minsk, BGU. 2005.

[7] Papanek V. Design for the real world: Human Ecology and Social Change, London, Thames and Hadson, 1985 
[8] Rawsthorn A. An Early Champion of Good Sense, New-York Times, May 15, 2011, URL: http://www.nytimes.com/2011/05/16/arts/16ihtdesign16.html?_r=0

[9] Readings, B. The University in Ruins, London: Harvard University Press, 1997.

[10] Savvina O.V. Ethical aspects of higher education in "Design for the real world" by V. Papanek, The proceedings of the 17th international conference of students, postgraduate students and young scientists, Moscow, MGU, 2010.

[11] Savvina O.V. Mission of the university, NB: Pedagogy and education, issue 2, 2012. DOI: 10.7256/2306-4188.2012.2.480. URL: http://enotabene.ru/pp/article_480.html.

[12] Verbeek P-P. Morality in Design Design Ethics and the Morality of Technological Artifacts, in Vermaas P. E. et al. (eds.), Philosophy and Design, Springer, 2008, pp. 91-103. 